University of Nebraska - Lincoln

DigitalCommons@University of Nebraska - Lincoln

U.S. Environmental Protection Agency Papers

U.S. Environmental Protection Agency

2009

Comparing The Mutagenicity of Toxaphene After Aging in Anoxic Soils and Accumulating in Fish

\author{
James C. Young \\ EnviTreat,Ilc,Fayetteville,AR72701,USA \\ Anne D. Freeman \\ EnviTreat,Ilc,Fayetteville,AR72701,USA \\ Robert M. Bruce \\ US EnvironmentalProtectionAgency,Cincinnati,OH45268,USA \\ Douglas Williams \\ US EnvironmentalProtectionAgency,Cincinnati,OH45268,USA \\ Keith Maruya \\ Southern CaliforniaCoastalWaterResearchProject,Westminster,CA92683,USA
}

Follow this and additional works at: https://digitalcommons.unl.edu/usepapapers

Part of the Civil and Environmental Engineering Commons

Young, James C.; Freeman, Anne D.; Bruce, Robert M.; Williams, Douglas; and Maruya, Keith, "Comparing The Mutagenicity of Toxaphene After Aging in Anoxic Soils and Accumulating in Fish" (2009). U.S. Environmental Protection Agency Papers. 20.

https://digitalcommons.unl.edu/usepapapers/20

This Article is brought to you for free and open access by the U.S. Environmental Protection Agency at DigitalCommons@University of Nebraska - Lincoln. It has been accepted for inclusion in U.S. Environmental Protection Agency Papers by an authorized administrator of DigitalCommons@University of Nebraska - Lincoln. 


\title{
Comparing the mutagenicity of toxaphene after aging in anoxic soils and accumulating in fish
}

\author{
James C. Young ${ }^{\mathrm{a}, *}$, Anne D. Freeman ${ }^{\mathrm{a}}$, Robert M. Bruce ${ }^{\mathrm{b}}$, Douglas Williams ${ }^{\mathrm{b}}$, Keith Maruya $^{\mathrm{c}}$ \\ a EnviTreat, llc, Fayetteville, AR 72701, USA \\ ${ }^{\mathrm{b}}$ US Environmental Protection Agency, Cincinnati, OH 45268, USA \\ c Southern California Coastal Water Research Project, Westminster, CA 92683, USA
}

\section{A R T I C L E I N F O}

\section{Article history:}

Received 18 February 2006

Received in revised form

28 February 2008

Accepted 1 March 2008

Available online 27 May 2008

\section{Keywords:}

Toxaphene

Fish

Contaminated soil

Mutagenicity

Chlorinated pesticide

Reductive dechlorination

\begin{abstract}
A B S T R A C T
A test program was conducted to evaluate the mutagenicity of toxaphene residuals extracted from aged soils and from fish collected in creeks near a toxaphene-contaminated site. The ultimate objective was to determine if the residual toxaphene congeners were more or less mutagenic than those in technicalgrade toxaphene. The study showed that the mutagenicity of the bioaccumulated toxaphene congeners in fish, expressed as colony revertants per $\mu \mathrm{g}$ of residual toxaphene, was no greater than that of technical-grade toxaphene. The mutagenic impact of the toxaphene residuals in aged soil statistically was less than that for technical-grade toxaphene. Two specific congeners, a hexachlorobornane (labeled $\mathrm{Hx}-\mathrm{Sd}$ ) and a heptachlorobornane (labeled $\mathrm{Hp}-\mathrm{Sd}$ ), were found to accumulate over time in both soil and fish extracts, but did not show increased mutagenic impacts relative to that produced by technicalgrade toxaphene.
\end{abstract}

(c) 2008 Elsevier Inc. All rights reserved.

\section{Introduction}

Toxaphene is a complex mixture of chlorinated bornanes containing about $68 \%$ chlorine by weight (CAS No. 8001-35-2), and commercial formulations can contain up to 670 individual congeners (Steinberg et al., 1998; Fingerling et al., 1996). While application of toxaphene was banned in the US in 1980, it still is used in some European and Latin American countries. Because of its widespread use as an agricultural pesticide, numerous contaminated sites exist throughout the US. These sites serve as entry points for toxaphene into the aquatic and soil environments, possibly resulting in accumulations in fish and agricultural products. Because of its heavy use worldwide, toxaphene congeners have been found in arctic lakes (Kidd et al., 1995). Studies have shown that under suitable conditions toxaphene undergoes biodegradation by reductive dehalogenation in anoxic environments in soils, sediments, and sewage sludge with the production of less-heavily chlorinated intermediates (Fingerling et al., 1996; Buser et al., 2000; Vetter and Kirchberg, 2001; Young and Freeman, 2005). Reductive dehalogenation is a reaction whereby microorganisms growing on biodegradable organic substances in anoxic soil or aquatic environments produce the enzymes that allow organo-chlorine atoms to be used as electron acceptors, thereby releasing the chlorine as a free chloride and

\footnotetext{
* Corresponding author.

E-mail address: jcyuark@aol.com (J.C. Young).
}

leaving an organic compound having fewer attached chlorine atoms.

Numerous studies have been conducted to assess the mutagenicity of commercial toxaphene as well as some of its chlorobornane congeners (Steinberg et al., 1998; Fingerling et al., 1996; Hooper et al., 1979; Mirsatari et al., 1987). Steinberg et al. (1998) concluded that while commercial toxaphene showed mutagenic properties, four specific chlorobornane congeners did not. However, less work has been done to document the mutagenicity of toxaphene residuals that remain in aged soils or accumulate in fish and other aquatic organisms. The test program described in this paper was initiated in February 2000 to compare the mutagenicity of toxaphene residuals that were extracted from soils that had been aged in the laboratory and soils removed from contaminated field sites to that of technical-grade toxaphene (Young et al., 2001). Simultaneously, fish from the Terry/Dupree Creek site in Georgia were processed to extract the toxaphene congeners that had bioaccumulated over time. The ultimate objective was to determine if the biodegradation products of weathered toxaphene in soils and those accumulating in fish were more or less mutagenic than those in technical-grade toxaphene.

\section{Materials and methods}

The laboratory test program involved addition of known amounts of toxaphene to soil samples and incubating them at $25^{\circ} \mathrm{C}$ under controlled conditions. 
Toxaphene residuals and chlorinated biodegradation products were extracted at 4-6-week intervals in duplicate samples to assess biodegradation rates. Samples that were incubated for 104 weeks were extracted to remove aged toxaphene residuals. Purified extracts were obtained from fish specimens collected in the wild from the Terry/Dupree Creek marsh system adjacent to the Hercules Inc. facility near Brunswick (GA) between 1997 and 2003. The toxaphene residues extracted from the soils and fish were analyzed for mutagenic impacts using standard Ames test procedures (Maron and Ames, 1983; APHA, 1998).

\subsection{Soil sample preparation}

The soil used in the test program was a mixture of $75 \%$ silty loam from a Western Iowa farm that had no known prior application of toxaphene and $25 \%$ commercial topsoil. The final mixture contained 3.5\% organic matter. Subsequent analysis showed that the laboratory soil contained no toxaphene residuals.

Eighty grams of the soil mixture were placed in each of the sixty $250 \mathrm{~mL}$ serum bottles (Wheaton 219437) along with $100 \mathrm{~mL}$ of distilled water that contained nutrients and minerals to support biological growth (Table 1 ). The headspace gas was flushed with nitrogen to remove oxygen from the bottles so that the oxidation-reduction potential of the mixture was around $-100 \mathrm{mV}$. Forty-two of these bottles were used for bioconversion tests and nine were double autoclaved to serve as abiotic controls. Technical-grade neat toxaphene (Chemical Services Co., West Chester, PA, lot 2237-4C) was dissolved in acetone at $1 \mathrm{~g} / \mathrm{L}$ to give a working stock solution. This solution $(0.8 \mathrm{~mL})$ was added to each bottle that was to be aged to give a dose of $100 \mu \mathrm{g}$ of toxaphene per dry gram of soil, $630 \mathrm{mg}$ acetone/ $\mathrm{L}$, and $80 \mathrm{mg}$ toxaphene/L. The acetone served both as a solvent for the toxaphene and as a readily biodegradable organic co-substrate to support the growth of facultative microorganisms in the anoxic conditions within the serum bottles. Ten 1-L bottles were set up similarly using $640 \mathrm{~g}$ of soil, $800 \mathrm{~mL}$ of nutrient/mineral/ buffer (NMB) water, and sufficient toxaphene stock solution to give $100 \mu \mathrm{g}$ of toxaphene per dry gram of soil. The 1-L bottles were required to produce the amount of residual aged toxaphene needed for the mutagenicity tests. All bottles were incubated at $25^{\circ} \mathrm{C}$ in the dark. The $250 \mathrm{~mL}$ and 1 - $\mathrm{L}$ bottles were incubated for a total of 52 and 104 weeks, respectively.

Nine of the $250 \mathrm{~mL}$ bottles were set aside without the addition of water or toxaphene. These bottles were used later as zero-contact controls. One hundred milliliter volumes of NMB water and $0.8 \mathrm{~mL}$ of stock acetone solution containing $80 \mathrm{mg}$ of toxaphene were added to one of these zero-contact bottles shortly before the incubated samples were to be extracted. The bottle was shaken for $24 \mathrm{~h}$ on a rotary shaker followed by extraction using the hexane extraction procedure described below. In effect, the zero-contact sample was the standard for toxaphene measurement and would contain any non-toxaphene residuals that might impact the GC test results. Additionally, the use of zero-contact samples in this manner automatically corrected for drift in GC retention times (RTs) for each congener peak. Tests indicated essentially 100\% recovery of the toxaphene from the zerocontact samples (Young et al., 2001).

\subsection{Toxaphene extraction method}

Two, 250-mL bottles and one abiotic control bottle were removed from incubation at 3- to 6-week intervals for extraction of residual toxaphene

\section{Table 1}

Nutrient/mineral/buffer (NMB) composition of test media

\begin{tabular}{ll}
\hline 'Constituent & Concentration $(\mathrm{mg} / \mathrm{L})$ \\
\hline Mineral base I & \\
$\mathrm{CoCl}_{2} \cdot 6 \mathrm{H}_{2} \mathrm{O}$ & 0.005 \\
$\mathrm{FeCl}_{2} \cdot 4 \mathrm{H}_{2} \mathrm{O}$ & 0.08 \\
$\mathrm{MnCl}_{2} \cdot 4 \mathrm{H}_{2} \mathrm{O}$ & 0.005 \\
$\mathrm{H}_{3} \mathrm{BO}_{3}$ & 0.0005 \\
$\mathrm{ZnCl}_{2}$ & 0.0005 \\
$\mathrm{NaMoO}_{4} \cdot 2 \mathrm{H}_{2} \mathrm{O}$ & 0.0001 \\
$\mathrm{NiCl}_{2} \cdot 6 \mathrm{H}_{2} \mathrm{O}$ & 0.0005 \\
$\mathrm{Na}_{2} \mathrm{SeO}_{4}$ & 0.0005 \\
$\mathrm{CuCl}_{2}$ & 0.00014 \\
$\mathrm{Mineral} \mathrm{base} \mathrm{II}$ & \\
$\mathrm{CaCl}_{2}$ & 0.30 \\
$\mathrm{MgCl}_{2} \cdot 6 \mathrm{H}_{2} \mathrm{O}$ & 0.40 \\
$\mathrm{Nutrient}$ base & \\
$\mathrm{NH}_{4} \mathrm{Cl}$ & 0.50 \\
$\mathrm{Na}_{2} \mathrm{SO}_{4}$ & 0.30 \\
$\mathrm{Buffer}$ base & \\
$\mathrm{KH}_{2} \mathrm{PO}_{4}$ at pH $=7$ & 2.07 \\
\hline
\end{tabular}

congeners. The test samples, the abiotic control, and the zero-contact samples were acidified to $\sim \mathrm{pH} 4$ using sulfuric acid. Fifty milliliters of pesticide-grade hexane plus $10 \mathrm{~mL}$ ethanol were added to each bottle. The samples were mixed for $24 \mathrm{~h}$ using an oscillating shaker table at $300 \mathrm{rpm}$. The bottles were allowed to sit for $1-4 \mathrm{~h}$ until a free hexane layer formed on top of the water. Seven to 10 milliliters of the free solvent layer were transferred to glass vials using a glass syringe. One-half gram of anhydrous $\mathrm{NaSO}_{4}$ crystals was added to each vial followed by agitation for about $1 \mathrm{~min}$. After the crystals settled, 5-7 mL of clear supernatant were transferred to amber glass vials, which were then stored in the dark at $<5^{\circ} \mathrm{C}$ until analysis. One milliliter of this extract was transferred to a $2 \mathrm{~mL}$ auto-sampler vial immediately prior to analysis.

\subsection{Fish extraction method}

The fish extraction protocol used in the current study closely mirrored that published previously by Maruya and Lee (1998) and Maruya et al. (2001). The tissue used to prepare these extracts consisted of scaled, skin-on-muscle fillets and homogenized whole bodies from several species for which toxaphene concentrations ranged between 2 and $6 \mu \mathrm{g} / \mathrm{g}$ wet weight (Table 2; Maruya et al., 2001). Tissues were processed using stainless steel instruments, stored cold in aluminum foil, and subsequently frozen in glass containers. Frozen tissues were thawed and $15-20 \mathrm{~g}$ aliquots were homogenized with $50 \mathrm{~g} \mathrm{Na}_{2} \mathrm{SO}_{4}$ using a ceramic mortar and pestle and extracted with $400 \mathrm{ml} \mathrm{CH}_{2} \mathrm{Cl}_{2}$ in a glass Soxhlet apparatus for $\geqslant 16 \mathrm{~h}$. The extracted $\mathrm{CH}_{2} \mathrm{Cl}_{2}$ was reduced to $<10 \mathrm{ml}$ using a heated water bath and a Kuderna-Danish evaporative concentrator assembly. The bulk extract was treated with concentrated $\mathrm{H}_{2} \mathrm{SO}_{4}(5 \mathrm{ml})$ to destroy lipid interferences. Maruya (unpublished data) found that acid hydrolysis has no measurable impact on the recovery of technical-grade toxaphene congeners or metabolites of biodegradation reactions in environmental samples. Differences in total toxaphene concentrations for acid- and untreated fish tissue extracts, split from the same sample, were less than $10 \%$. No discernable qualitative differences in chromatographic profile (ECD or ECNI-MS) were observed in these extracts. These observations have been supported in work with fish tissue samples (McHugh et al., 2003) and human serum samples (Barr et al., 2004). The organic layer from the hydrolyzed sample was then exchanged to hexane using a TurboVap II (Zymark Inc., Hopkington, MA), reduced to $1 \mathrm{ml}$, and fractionated on $18.0 \mathrm{~g}$ of $1.0 \%$ water-deactivated Florisil (60-100 mesh, Fisher Scientific, Fair Lawn, NJ) dry packed in a narrow glass column. After pre-separation of PCBs and other nonpolar analytes, toxaphene residues were eluted from the Florisil with $150 \mathrm{ml}$ of $20 \%(\mathrm{v} / \mathrm{v}) \mathrm{CH}_{2} \mathrm{Cl}_{2}$ in hexane. Toxaphene-containing extracts were blended by species, and a dilute aliquot was transferred into a $2 \mathrm{ml}$ amber vial for GC analysis (see Analytical method section below).

\subsection{Analytical method}

\subsubsection{Soil extracts}

The extracts were analyzed by GC using a 30-m capillary column with a split/splitless injector and ECD detector. The GC column was 30-m fused silica capillary, $0.25 \mathrm{~mm}$ ID, and $0.32 \mu \mathrm{m}$ film thickness of DB-5 (Agilent/J. W. Scientific, Santa Clara, CA). The detector was operated at a constant temperature of $230^{\circ} \mathrm{C}$. The column temperature was increased at a rate of $20^{\circ} \mathrm{C} / \mathrm{min}$ from 120 to $200^{\circ} \mathrm{C}$ then at $5{ }^{\circ} \mathrm{C} / \mathrm{min}$ to $230^{\circ} \mathrm{C}$, followed by $1.5^{\circ} \mathrm{C} / \mathrm{min}$ to $250^{\circ} \mathrm{C}$. The sample injection volume was $1 \mu \mathrm{L}$. Each test run was followed by injection of $1 \mu \mathrm{L}$ of pure pesticide-grade hexane to clean the column before the next sample injection.

Because toxaphene is a mixture of chlorinated bornanes and related compounds, the GC scan is quite complex and some of the peaks were difficult to separate as shown by the example in Fig. 1 for the laboratory-standard sample. The overall approach to quantifying biodegradation in the current test program was to track the area of 11 selected peaks on the chromatograms and compare the respective areas to those of the corresponding peak for the zero-contact control. The selected peaks are identified in Fig. 1 and are the same peaks used in the Phase I study (Young et al., 2001). RTs for the respective peaks are shown in Table 3. Over time, the RTs shifted because of differences in GC column conditions. Identification of specific peaks involved careful examination of expanded chromatograms for each extract. The toxaphene was quantified both as the total area of the 13 selected peaks as well as the total area of the chromatogram above the valley-to-valley base line, as illustrated in Fig. 1.

Two additional peaks-A at 18.01 and B at $18.45 \mathrm{~min}$ RT-were added later. These peaks represented 2-exo,3-endo,6-exo,8,9,10-hexachlorobornane (labeled $\mathrm{Hx}$-Sd) and 2-exo,3-endo,5-exo,6-endo,8,9,10-heptachlorobornane (labeled Hp-Sd) that were of specific concern, because their rates of biodegradation were suspected to be low in soil and aquatic environments. The Hx-Sd congener was observed by Fingerling et al. (1996) and was identified as a "dead-end" metabolite of toxaphene biodegradation. That is, this metabolite seemed to exhibit no further biodegradation with time. The Hx-Sd and Hp-Sd congeners were observed by Buser et al. (2000) in sewage sludge samples and by Stern et al. (1996) in rainbow trout and sediment from lakes. 
Table 2

Species contribution of toxaphene residues in the blended fish extract

\begin{tabular}{|c|c|c|c|}
\hline Fish species & Extracted wet weight (g) & Mean $\operatorname{TOX}^{\mathrm{a}}$ ( $\mu \mathrm{g} / \mathrm{g}$ wet wt.) & Total TOX $(\mu \mathrm{g})$ \\
\hline Silver perch (Bairdiella chrysoura) & 725 & 2.11 & 1,530 \\
\hline Spot (Leiostomus xanthurus) & 730 & 4.01 & 2,930 \\
\hline Striped mullet (Mugil cephalus) & 940 & 3.90 & 3,670 \\
\hline Mummichogs (Fundulus sp.) & 80 & 4.81 & 385 \\
\hline Atlantic croaker (Micropogonias undulatus) & 210 & 5.29 & 1,110 \\
\hline Various other species & 210 & 2.56 & 537 \\
\hline Total & 2,895 & & 10,160 \\
\hline
\end{tabular}

a $\mathrm{TOX}=$ toxaphene residual.

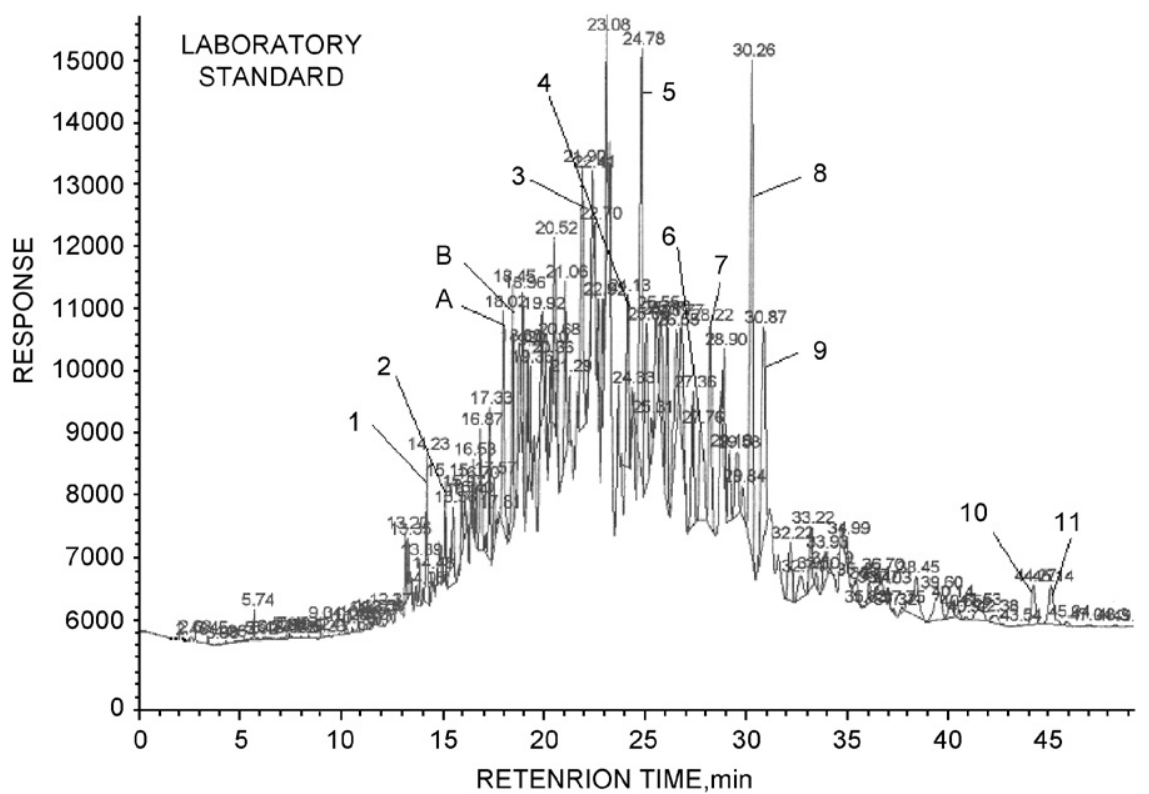

Fig. 1. Chromatogram of laboratory standard for the toxaphene used for the aging tests.

Table 3

Retention times for selected peaks shown in Fig. 1

\begin{tabular}{ll}
\hline Peak no. & Retention time $(\mathrm{min})$ \\
\hline 1 & 14.23 \\
2 & 15.13 \\
A & 18.02 \\
B & 18.45 \\
3 & 21.89 \\
4 & 24.29 \\
5 & 24.78 \\
6 & 27.73 \\
7 & 28.22 \\
8 & 30.26 \\
9 & 30.87 \\
10 & 44.25 \\
11 & 45.13 \\
\hline
\end{tabular}

\subsubsection{Fish extract}

In addition to the GC method used for analyzing the soil extract, $1 \mu \mathrm{L}$ samples of purified fish extract were injected into a Varian 3400CX GC-ECD with an 8200 autosampler. Varian Star chromatography software (v4.01) was used to acquire and analyze chromatographic runs. A $30 \mathrm{~m}(\mathrm{~L}) \times 0.25 \mathrm{~mm}$ (ID) fused silica capillary column coated with a $0.25 \mu \mathrm{m}$ DB-XLB (Agilent/J\&W Scientific, Folsom, CA) was used to separate toxaphene congeners. The splitless injector and detector temperatures were 250 and $300{ }^{\circ} \mathrm{C}$, respectively. The GC oven was programmed as follows: $120^{\circ} \mathrm{C}$ ( $1 \mathrm{~min}$ hold); ramp to $200^{\circ} \mathrm{C}$ at $10^{\circ} \mathrm{C} / \mathrm{min}$ ( $1 \mathrm{~min}$ hold); ramp to $280^{\circ} \mathrm{C}$ at $2{ }^{\circ} \mathrm{C} / \mathrm{min}$ ( $10 \mathrm{~min}$ hold). The total run time was $60 \mathrm{~min}$. To confirm the presence of toxaphene congeners, selected extracts (at least one sample per species per Florisil batch) were analyzed on a Hewlett-Packard 6890 Plus Series gas chromatograph coupled to a 5973 mass selective detector (GC-MSD) operating in the electron capture negative ionization (ECNI) mode. The GC column was identical to the one used for GC-ECD analyses. The GC oven was programmed as follows: $60^{\circ} \mathrm{C}$; ramp to $150{ }^{\circ} \mathrm{C}$ at $10^{\circ} \mathrm{C} / \mathrm{min}$ ( 1 min hold); ramp to $300^{\circ} \mathrm{C}$ at $4{ }^{\circ} \mathrm{C} / \mathrm{min}$ (11.5 min hold). The total GC run time was $60 \mathrm{~min}$. The injector was programmed to track the GC oven temperature. Methane at a pressure of $\sim 1 \mathrm{Torr}(1 \mathrm{~mm} \mathrm{Hg})$ was used as the moderating gas; the ion source and quadrupole temperatures were maintained at 106 and $150{ }^{\circ} \mathrm{C}$, respectively. The MS was scanned between 100 and $550 \mathrm{Da}$ at 1.3 cycles/s. Chromatograms were obtained using Agilent ChemStation software.

Total toxaphene was estimated by the external calibration method using a technical toxaphene product standard ("TTX") provided by J. Hoffman of Hercules Inc. (Wilmington, DE). Serial dilutions of TTX in hexane $(0.011-55.4 \mu \mathrm{g} / \mathrm{ml}$ ) were used to create an 8-point calibration curve. A mean response factor (RF) for TTX was computed by summing the areas of all peaks in the unresolved hump eluting between 15 and $50 \mathrm{~min}$ of the GC run and dividing by the known standard mass. This mean RF was then applied to the summed areas of peaks eluting in this specific RT window for each analyzed extract.

Total toxaphene estimates and purity of extracts were validated against a set of performance-based quality assurance/quality control (QA/QC) criteria. All glasswares were hand washed and rinsed thoroughly with water and pre-rinsed with solvents of high purity (e.g. Optima grade, Fisher Scientific) prior to use. Procedural blanks and TTX spiked reference tissues were analyzed in conjunction with the extracts that subsequently were used for assessment of mutagenicity.

Multi-point GC-ECD and GC-ECNI-MS calibration with TTX resulted in $r^{2}$ values exceeding 0.999. Based on repeated injections of a mid-level TTX calibration solution, the relative percent deviation from the initial TTX response was $\leqslant 20 \%$ for the duration of the analysis. About 20 procedural blanks were processed with approximately $40 \mathrm{~g}$ of kiln-fired $\mathrm{Na}_{2} \mathrm{SO}_{4}$ and analyzed with every other batch of samples following the same protocols used for the tissue samples. No organochlorine pesticides (e.g. 4,4'-DDT, dieldrin) were detected by GC-ECNI-MS in the extracts or QA/QC samples. The mean recoveries of the TTX spiked into reference 
fish tissue were $85 \pm 15 \%$. Several Cl7-Cl10 PCB congeners that typically reside in the first (discarded) Florisil fraction and elute outside the 15-50 min RT window were confirmed by ECNI-MS (Maruya and Lee, 1998); however, no PCB congeners were detected in the extracts that were to be used for mutagenic testing. Because the objective was to compare the mutagenicity of extracts from aged toxaphene-contaminated soil and fish tissue, no reference fish were used. This approach was not expected to adversely impact comparison of the mutagenic potential of the extracts to that of technical-grade toxaphene.

\subsection{Mutagenicity test method}

Aliquots of the hexane extracts from the 1-L bottles after 104 weeks of aging and the extracts from the fish were air-dried at room temperature to remove the hexane. The toxaphene residuals were then re-dissolved in acetone to give concentrations needed for conducting the Ames test. This solvent exchange was necessary to prepare the samples for testing by the Ames test. The procedure was shown in previous tests to cause no loss of toxaphene congeners (Young and Freeman, 2005)

Ames tests were conducted by Covance Laboratories, Inc. (Vienna, VA) using methods described by Maron and Ames (1983) and the standard methods for the examination of water and wastewater (APHA, 1998). This test evaluates the ability of test substrates to induce reverse mutations at the histidine locus in the Salmonella typhimurium strain TA100 in the presence and absence of a rat-liver extract (S9) that contains microsomal enzymes. While other strains were available for mutagenicity testing, strain TA100 was selected for its known specificity to toxaphene (Mortelmans et al., 1986; Steinberg et al., 1998). When these histidinedependent cells are exposed to the test substance and grown under selective conditions, only those cells that revert to histidine independence are able to form colonies. The use of rat-liver extract (+S9) allows detection of mutagenic metabolites of the test substance.

The test organisms were prepared by overnight culturing in Vogel-Bonner mineral medium E (Vogel and Bonner, 1956) supplemented with 1.5\% (w/v) Oxoid Nutrient Broth \#2 (dry powder). The base culture plates were prepared by placing $25 \mathrm{~mL}$ of Vogel/Bonner medium supplemented with $1.5 \%$ agar and $0.2 \%$ glucose in each of a number of $15 \times 100 \mathrm{~mm}$ petri dishes. These plates were overlain with a top agar comprised of $0.5 \%$ agar and $0.5 \% \mathrm{NaCl}$ solution supplemented with $10 \mathrm{~mL}$ of $0.5 \mathrm{mM}$ histidine/biotin solution per $100 \mathrm{~mL}$ agar for selection of histidine revertants. When S9 mix was not used, $100 \mu \mathrm{L}$ of test culture and $50 \mu \mathrm{L}$ of test or control substance were added to $2.5 \mathrm{~mL}$ of top agar at $45^{\circ} \mathrm{C}$. When S9 mix was used, $500 \mu \mathrm{L}$ of S9 mix, $100 \mu \mathrm{L}$ of test culture, and $50 \mu \mathrm{L}$ of test or control substance were added to $2.0 \mathrm{~mL}$ of top agar. Triplicate plates were poured for each test extract. Vehicle controls contained the test culture, S9 mix and solvent (acetone). Positive controls contained $2.5 \mu \mathrm{g} /$ plate 2 -aminoanthracene and $2.0 \mu \mathrm{g} /$ plate sodium azide as a standard diagnostic mutagenic substrate.

The dosed plates were inverted and incubated for $48-56 \mathrm{~h}$ at $35-39^{\circ} \mathrm{C}$. After incubation, the revertant colonies on the test plates and control plates were counted, and the presence of a background lawn on all plates was confirmed. A lawn that is thin on the test plates as compared to the lawn on the control plates is evidence of bacterial toxicity. Colonies appearing on a plate that had no background lawn were not considered revertants and were not scored. These colonies arise from the surviving test bacteria that live off the histidine present in the top agar.

\section{Results}

\subsection{Soil extracts}

Comparison of chromatograms for the soil extracts at 52 and 104 weeks of incubation to that for the laboratory standard, as shown in Fig. 2, illustrate the shift of toxaphene congeners from high molecular weight (high RTs) to those having fewer chlorines and therefore, lower molecular weight (lower RTs). The two large peaks, $\mathbf{A}$ at 18.01 and $\mathbf{B}$ at $18.45 \mathrm{~min}$ RT, shown earlier in Fig. 1, respectively, represent the $\mathrm{Hx}-\mathrm{Sd}$ and $\mathrm{Hp}-\mathrm{Sd}$ congeners. These chromatograms illustrate the overall shift of high molecularweight congeners - those to the right on the chromatograms - to lower molecular-weight congeners. The average bioconversions of toxaphene at various times of incubation, as indicated by reductions in total areas for all 13 selected peaks as well as total area of all peaks above the toxaphene hump, are shown in Table 4. The variability represents the effect of summing areas of peaks that are shifting with time of incubation.
Peak areas expressed as a percentage of the area of the respective zero-contact peak are summarized in Fig. 3. The peaks between \#1 (14 min RT) and B (18.45 min RT) showed an increase in area during the first 24 weeks of incubation (Fig. 3A). Peaks in this retention range generally represent chlorobornane congeners and metabolites having seven or fewer chlorine atoms per molecule. The Hx-Sd and Hp-Sd congeners (Peaks A and B), which fall into this range, showed an initial increase in concentration through 24 weeks of incubation and leveled off at around 150\% of initial concentration between 24 and 60 weeks (Fig. 3A). Further decreases were observed between 60 and 79 weeks of incubation. Peaks 1 and 3 tended to follow the average trend through 79 weeks of incubation. The lack of more complete removal of Peaks 2, A, and $B$ is considered to be due more to progressive increases from dehalogenation of higher chlorinated congeners than to lack of biodegradability. However, the low rate of change after 24 weeks of incubation does imply a slow biodegradation rate for these congeners.

Peaks 4, 6, and 7 at RTs between 20 and 30 min initially showed little change in concentration, but gradually decreased to less than average values after 12 weeks of incubation (Fig. 3B). Peak 5 increased initially in area and then tended to track the average trend after 50 weeks of incubation. The higher-chlorinated congeners (generally $>\mathrm{Cl}$ ) —as represented by Peaks 8-11-all were degraded to a similar extent with essentially no residual remaining after 50 weeks of incubation (Fig. 3C).

The shift in chlorination levels was verified by chlorobornane homolog profiles as shown in Figs. 4 and 5, respectively, for the technical toxaphene sample and the test soil sample after 52 weeks of aging. Essentially no $\mathrm{Cl} 9$ and $\mathrm{Cl} 10$ congeners were present in the aged sample, and the $\mathrm{Cl} 8$ congeners were reduced significantly from that of the technical-grade toxaphene. The $\mathrm{Cl} 7$ group, which includes the Hp-Sd congener, was reduced substantially with one cluster remaining in relatively large quantities around 34-35 min RT. The Hp-Sd congener showed about a threefold increase in peak area over that in the technical toxaphene sample. The Hx-Sd congener showed the greatest increase in concentration of the members of the $\mathrm{Cl} 6$ group. This observation, along with changes in peaks as shown in Figs. 2 and 3, indicates strongly that a substantial amount of the Hx-Sd and Hp-Sd congeners were formed through biotransformation in the soil environment.

\subsection{Fish extracts}

A chromatogram for the fish extract is shown in Fig. 6 along with one for comparison from the 104-week soil extract. The $\mathrm{Hx}-\mathrm{Sd}$ and Hp-Sd congeners represented a much greater percentage of total residual toxaphene for both these extracts than in technical toxaphene (Table 5). Homolog profiles for the fish extract showed substantial amounts of the Hx-Sd and Hp-Sd congeners but very little $\mathrm{Cl} 9$ and $\mathrm{Cl} 10$ congeners as compared to the control (Fig. 7). These data do not tell whether the Hx-Sd and Hp-Sd congeners were formed through metabolic processes within the fish or simply were the result of bioaccumulation from aged toxaphene in their food source. Because the fish had consumed aged toxaphene from the Terry/Dupree Creek sediments and aquatic organisms that had fed on these sediments, it could be expected that the most refractory congeners or biodegradation products would have been present in the fish. The data show clearly, however, that the Hx-Sd and Hp-Sd congeners were present in greater percentages of the residual toxaphene in the aged soil and fish extracts than existed in the technical toxaphene (Table 5). 


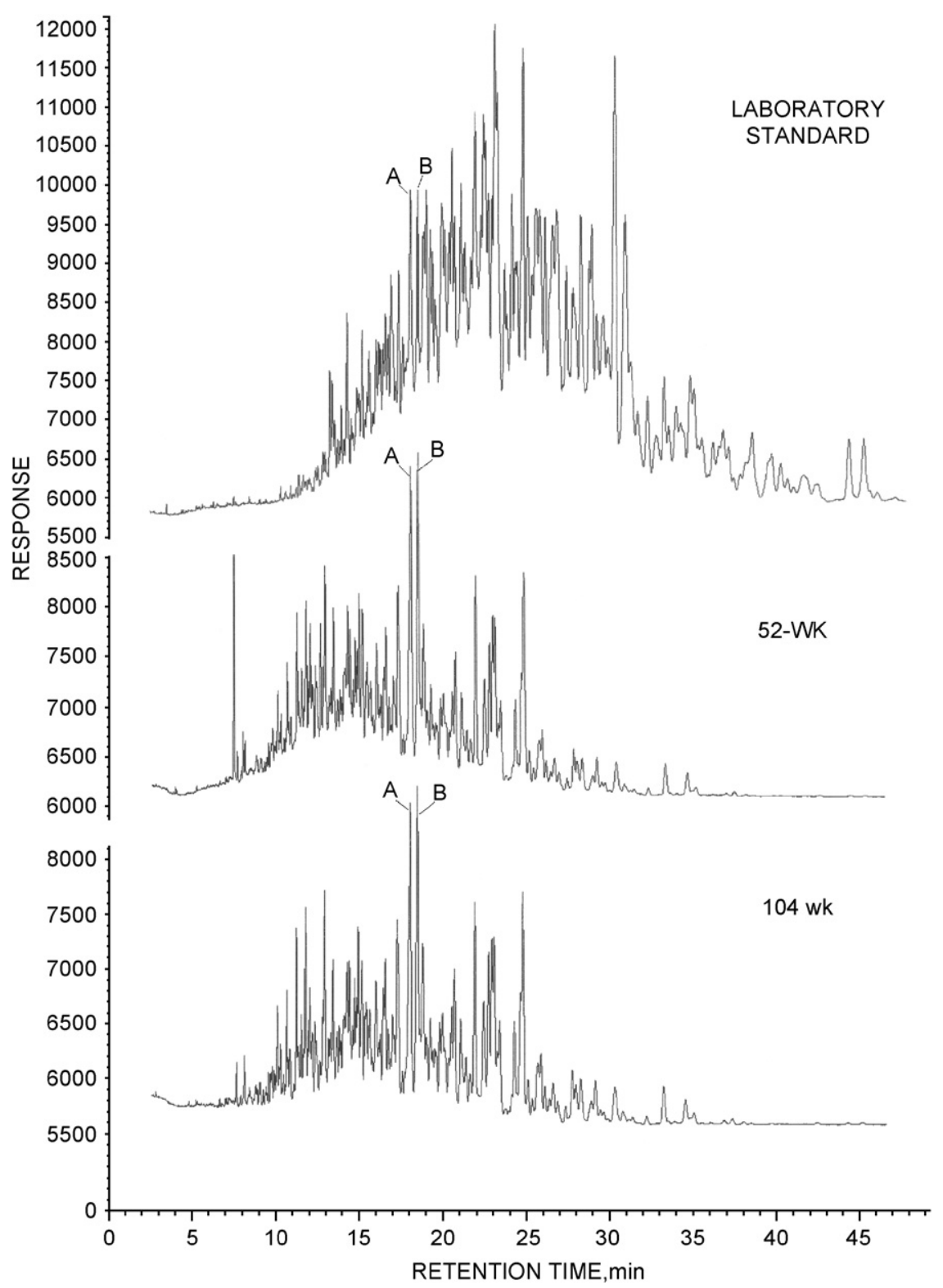

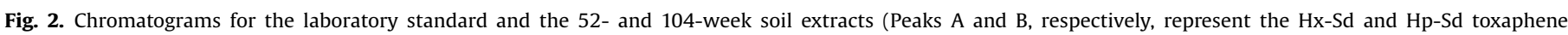
congeners.).

Table 4

Bioconversion vs. time for toxaphene during aging in an anoxic soil environment

\begin{tabular}{lll}
\hline Weeks of aging & $\begin{array}{l}\text { \% Bioconversion based on } \\
\text { area of 13-peeks }\end{array}$ & $\begin{array}{l}\text { \% Bioconversion based on } \\
\text { total area }\end{array}$ \\
\hline 6 & 9.3 & 2.3 \\
12 & 3.4 & -4.7 \\
20 & 39.2 & 31.2 \\
24 & 29.3 & 36.6 \\
50 & 54.0 & 57.8 \\
61 & 48.5 & 48.2 \\
79 & 49.3 & 61.1 \\
\hline
\end{tabular}

\subsection{Mutagenicity testing}

The approach used for the application of the Ames test data in the current study was modeled after the method presented by
Hooper et al. (1979) and Mortelmans et al. (1986) in which the mutagenicity of the toxaphene residuals and other chemicals, expressed as revertant colonies per plate after correction for the solvent blank, was shown to increase with increasing toxaphene doses ranging from less than 100 to as high as $1000 \mu \mathrm{g} /$ plate. While this method does not account for all factors affecting mutagenicity of toxaphene congeners, the comparison of revertants at the same total toxaphene dose per plate should show valid differences in mutagenic impacts for the respective extract sources. Net reversions for the $+S 9$ and $-S 9$ treatments, after correction for the no-toxaphene control, are shown in Fig. 8. These data show increasing numbers of revertants per plate for the technical-grade toxaphene. Error bars show the 95\% confidence interval for each test set. Error bars that do not overlap with other data sets indicate a statistically significant difference. Error bars that overlap with adjacent test sets indicate a lack of statistical difference. In this case, the test sets showed increasing significant differences with increasing toxaphene dose per plate. 
A

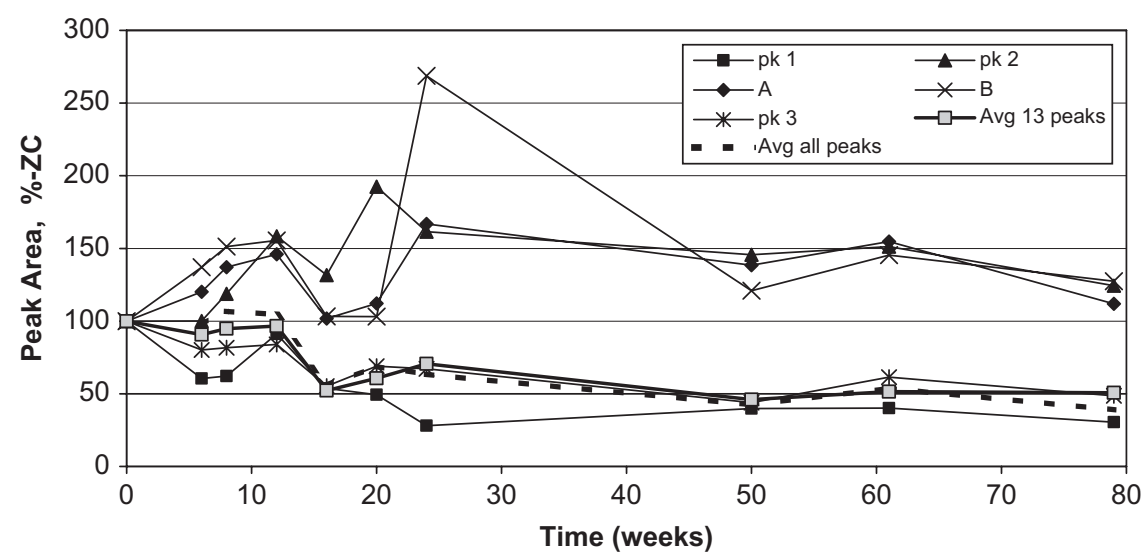

B

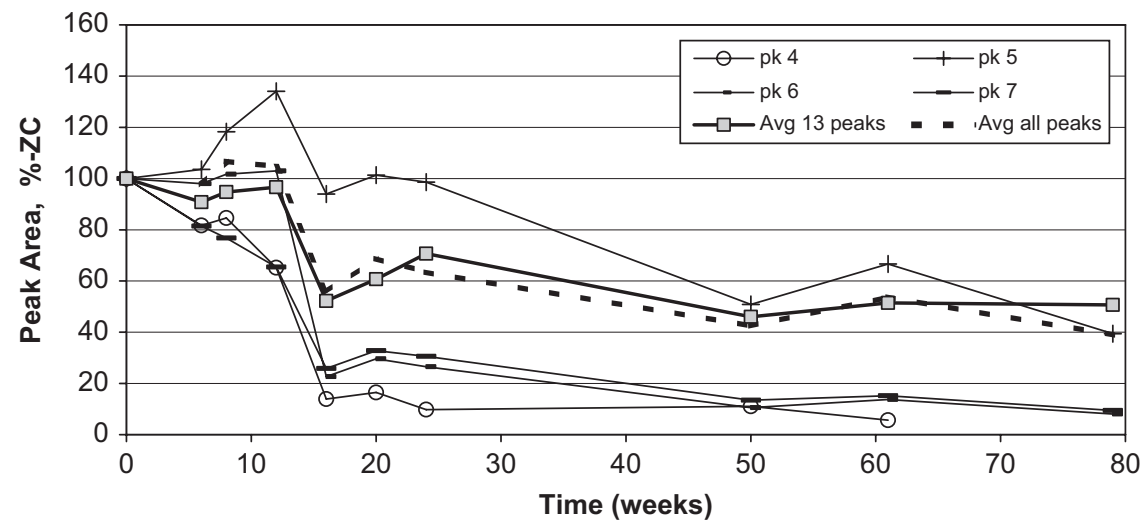

C

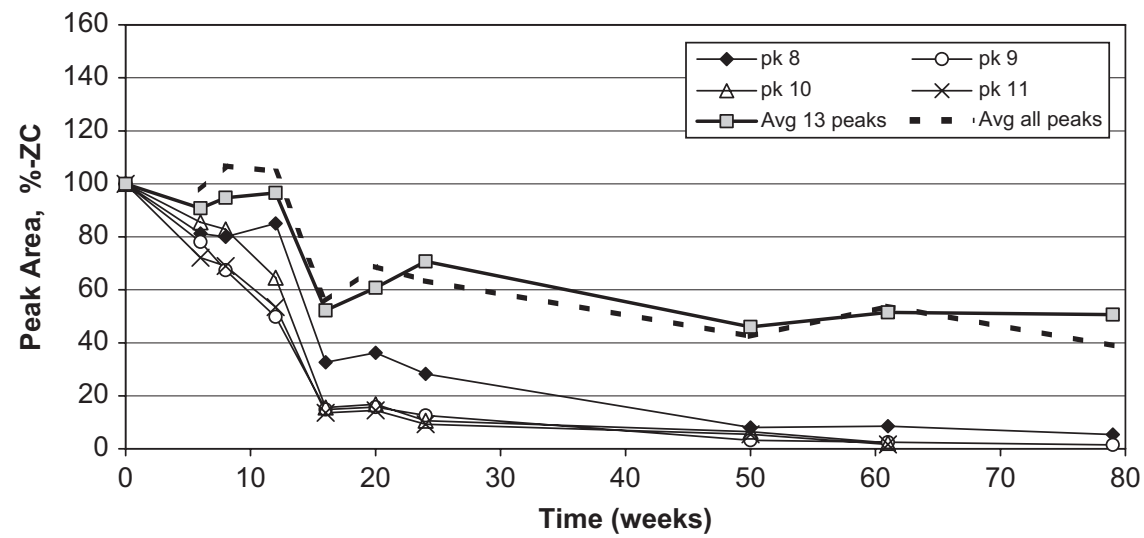

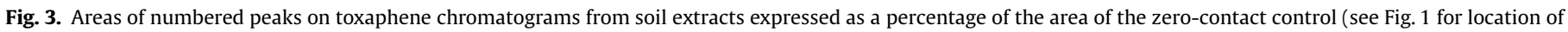
peaks on the chromatograms).

The soil and fish extracts showed an initial increase in revertants followed by a decrease as the amount of toxaphene per plate was increased. Plates receiving S9 treatment generally showed higher reversions per plate (Fig. 8A) than the untreated samples (Fig. 8B). Relating the mutagenic effect to the amount of toxaphene added per plate made it impossible to account for the fact that the soil may have contained one or more constituents that potentially were mutagenic. However, as described below, no mutagenic impacts were contributed by the soil.

Expressing the data as revertants per microgram of residual toxaphene produced gradually declining values with increasing toxaphene dose per plate (Fig. 9). These values were obtained by dividing the colony reversions shown in Fig. 8 by the amount of toxaphene applied per plate. The most important observation from this analysis was that the mutagenicity of the soil and fish extracts, per microgram of extracted toxaphene residual, was essentially the same as that for the technical-grade toxaphene. While the data show a statistically lower number of revertants per microgram of residual toxaphene for the soil extract than for the technical-grade toxaphene, the mutagenicity of the fish extract statistically was the same as that for the soil extract or the technical-grade toxaphene. The $+S 9$ treatment produced larger numbers of reversions per microgram of residual toxaphene, 
Abundance

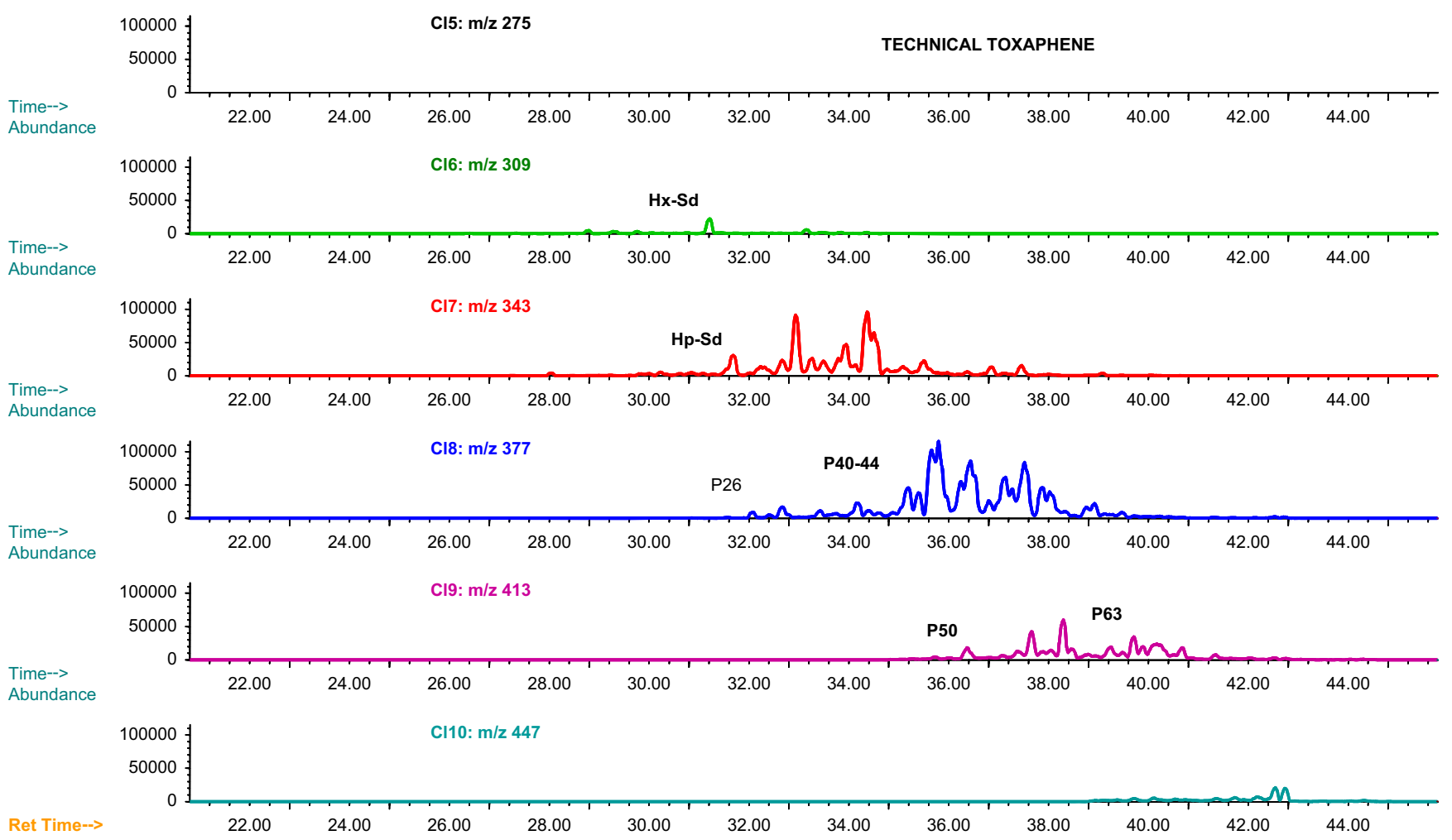

Fig. 4. Chlorobornane homolog analysis for technical toxaphene.

Abundance

$\begin{aligned} & \text { Time--> } \\ & \text { Abundance }\end{aligned}$
Time-->
Abundance

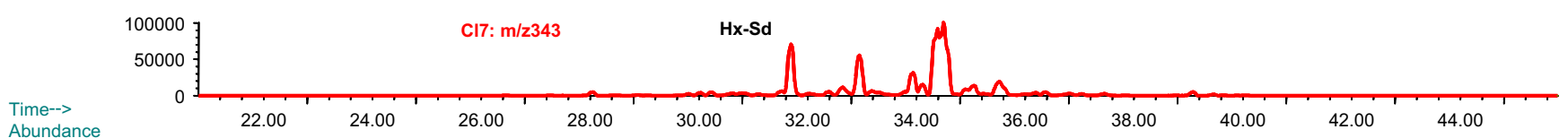

Abundance

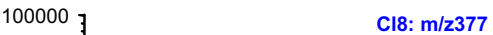

Time-->

Abundance

50000

Cl8: $\mathrm{m} / \mathbf{z} 377$
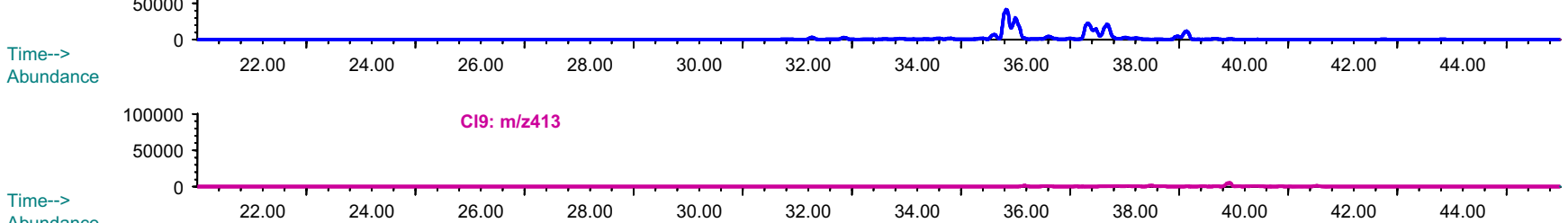

Abundance

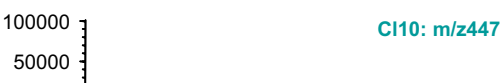

Ret Time-->
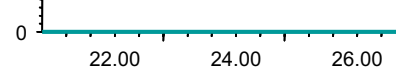

Fig. 5. Chlorobornane homolog analysis for 52-week aged soil sample.

thereby indicating a slight contribution of metabolites of toxaphene biodegradation to mutagenic impacts. However, the relative mutagenic impact did not change for technical toxaphene, soil, or fish extract (Fig. 9A).
These results are quite similar to those observed in Phase I tests (Young et al., 2001) using extracts from various soil treatments and from field sites (Fig. 10). However, in the previous tests, the $-\mathrm{S} 9$ conditions showed the largest number of revertants 


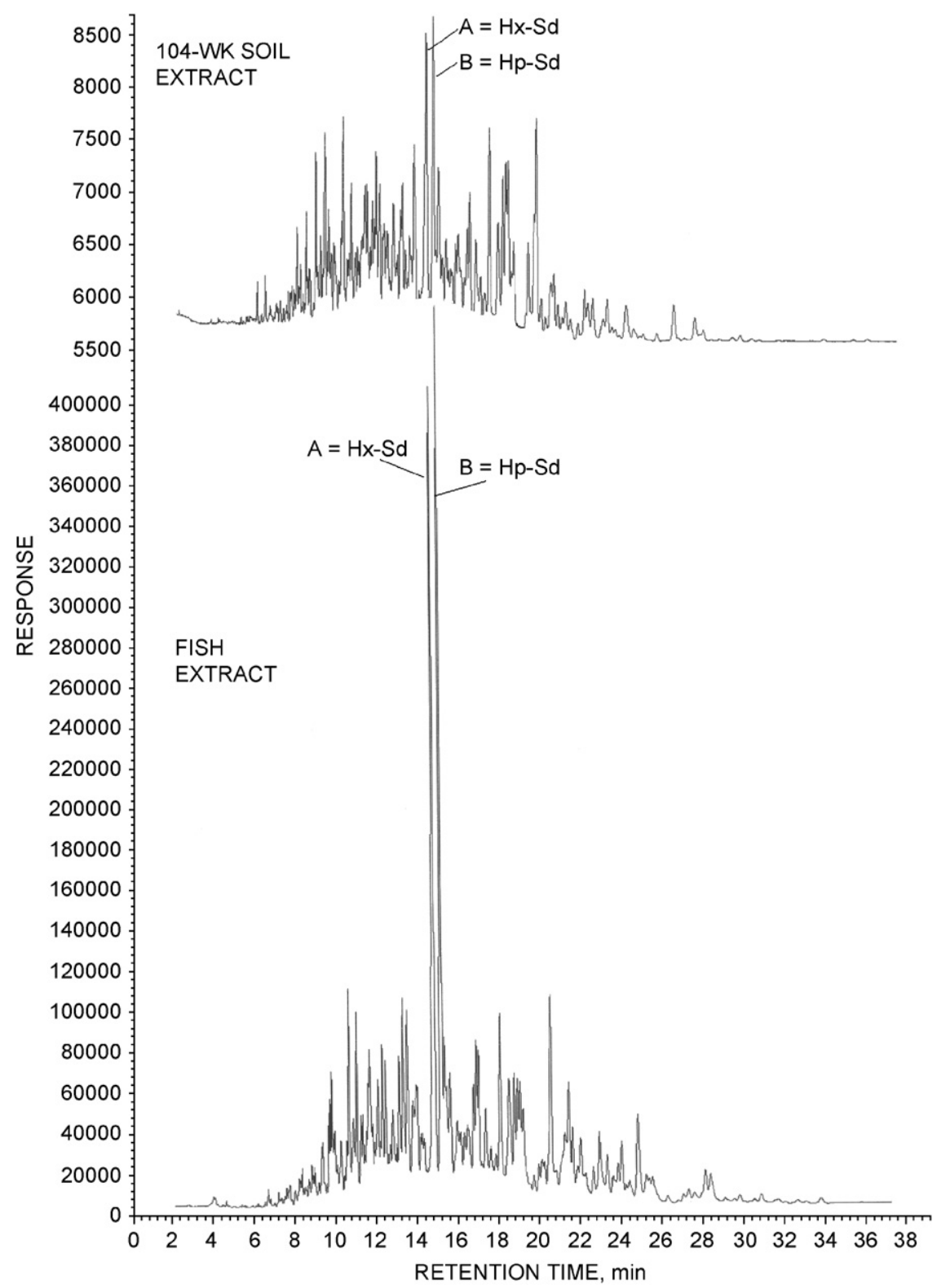

Fig. 6. Chromatograms for 104-week soil extract and the fish extract.

Table 5

Relative amounts of Hx-Sd and Hp-Sd congeners in technical toxaphene, soil extract, and fish extract

\begin{tabular}{llllll}
\hline Sample & \multicolumn{3}{l}{ Hx-Sd } & & \multicolumn{2}{l}{ Hp-Sd } \\
\cline { 2 - 3 } \cline { 5 - 6 } \cline { 5 - 6 } & \% Of 13 peaks & \% Total area & \% Of 13 peeks & \% Total area \\
\hline Technical toxaphene & 8.3 & 3.4 & & 5.9 & 2.4 \\
104-week soil extract & 26.4 & 8.7 & & 17.2 & 5.7 \\
Fish extract & 37.9 & 19.5 & & 28.5 & 14.6 \\
\hline
\end{tabular}

per microgram. These earlier tests showed that the mutagenic impacts of toxaphene residuals extracted from the soil at contaminated sites, per microgram of toxaphene, were less than that of technical toxaphene. In this case, the mutagenicity of extracts from the zero-contact sample was the same as that for technical toxaphene, thereby indicating that the soil itself contained no substances that contributed to the mutagenicity.

\section{Discussion}

The test program described above focused on comparison of mutagenic impacts of toxaphene congeners rather than absolute values. Therefore, no attempt was made to identify specific congeners-other than $\mathrm{Hx}$-Sd and Hp-Sd. The loss of number and areas of GC peaks at high RTs and the gain in number and areas of peaks at low RTs, as illustrated in Figs. 2, 3 and 6, support the occurrence of biodegradation through reductive dehalogenation. This observation also was supported by the homolog profiles shown in Figs. 4, 5 and 7. There was fairly clear evidence that the Hx-Sd and Hp-Sd congeners increased in quantity during aging in soils and bioaccumulation in fish, thereby providing strong evidence that these congeners were formed in part through reductive dehalogenation of higher molecularweight congeners.

The method of comparing mutagenic impacts in terms of colony revertants per microgram of toxaphene at equal toxaphene doses per test plate, while not perfect, helped to remove a number 
Abundance

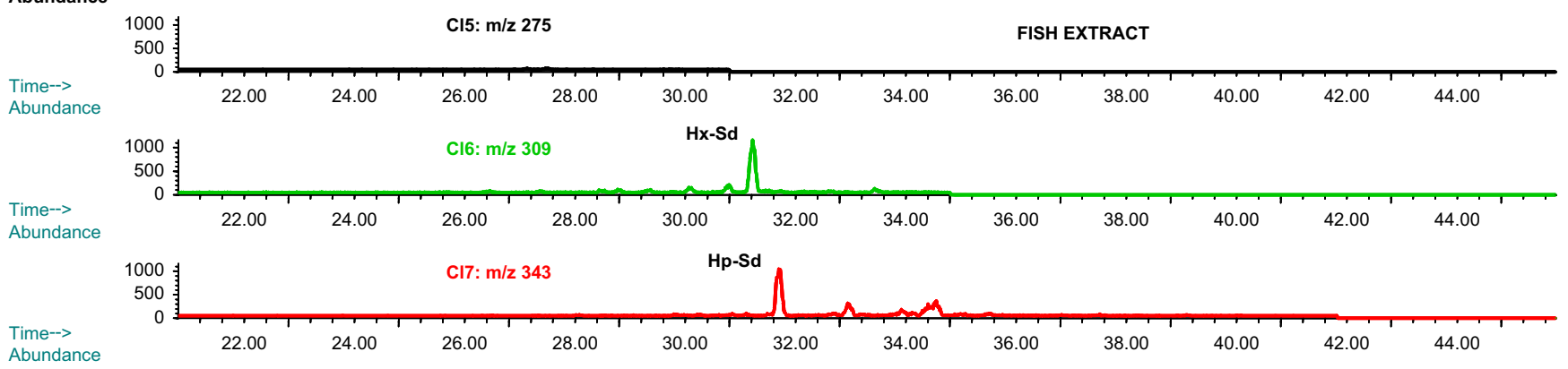

Cl8: $\mathrm{m} / \mathrm{z} 377$

Time-->

1000 章 Cl9: $\mathrm{m} / \mathrm{z} 413$

Time-->

Abundance

500

$\begin{array}{llllllllllllll}0 & 22.00 & 24.00 & 26.00 & 28.00 & 30.00 & 32.00 & 34.00 & 36.00 & 38.00 & 40.00 & 42.00 & 44.00 & 1\end{array}$

500

Ret Time-->

Cl10: $\mathrm{m} / \mathrm{z} 447$

Fig. 7. Chlorobornane homolog analysis for fish extract.

A

+S9

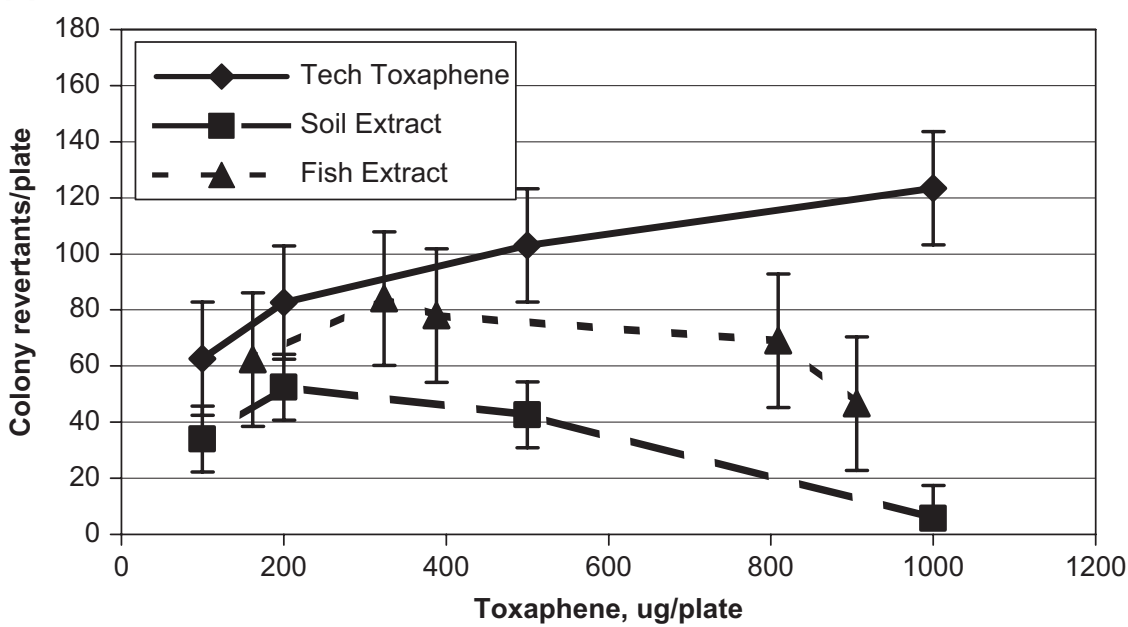

B

-S9

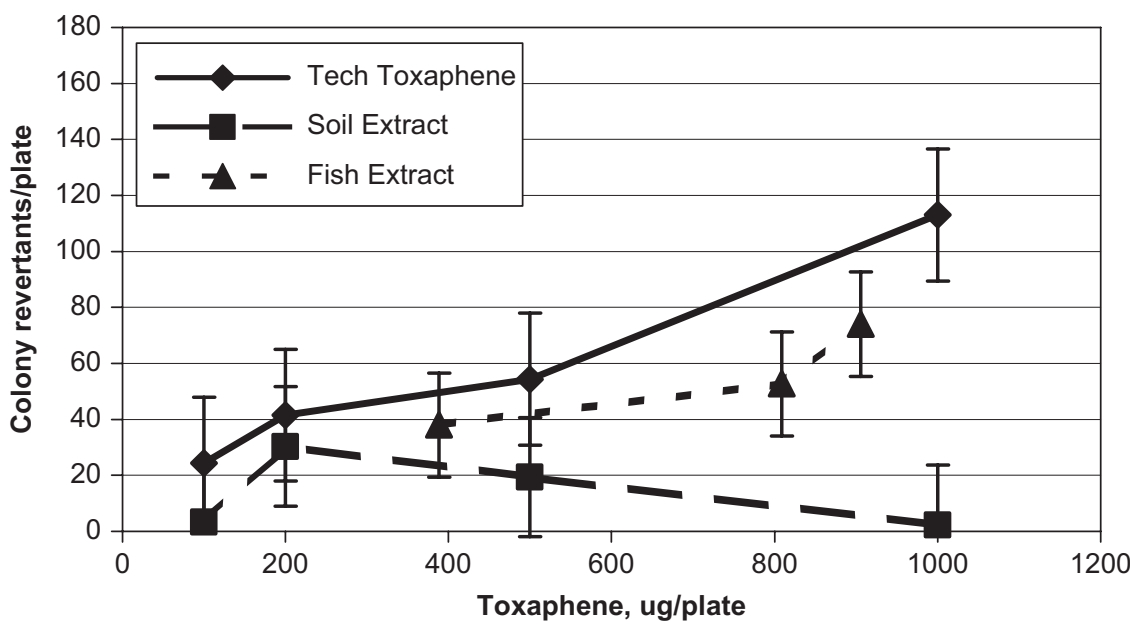

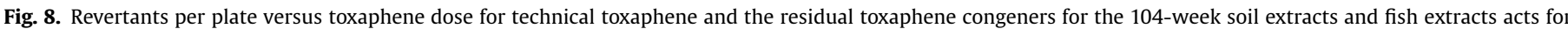
samples receiving + S9 (A) and -S9 (B) treatments. 
A

$+\mathbf{S 9}$

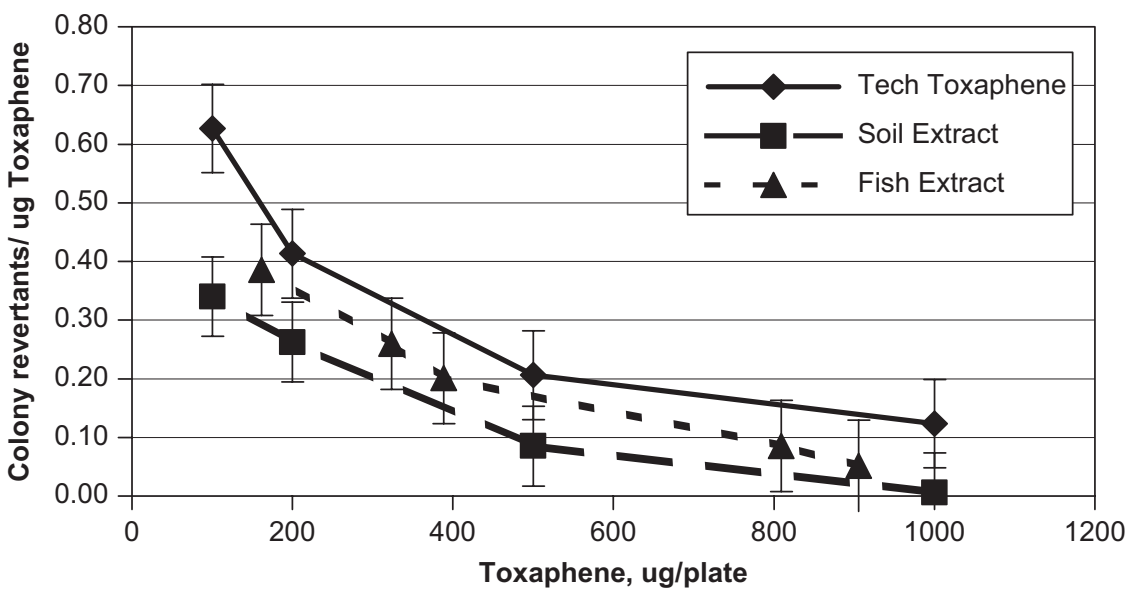

B

-s9

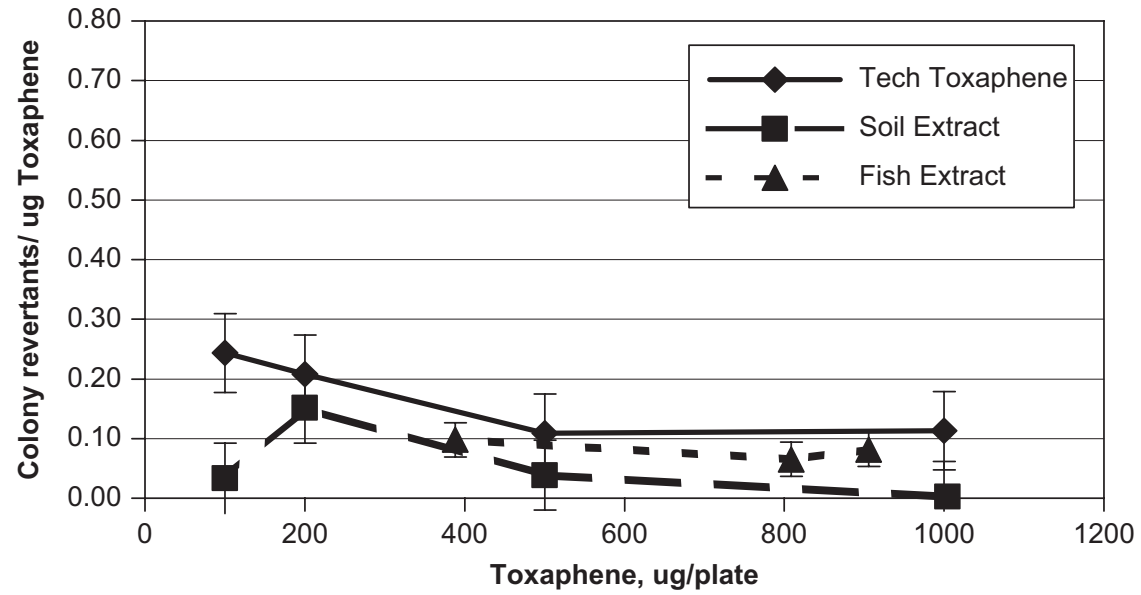

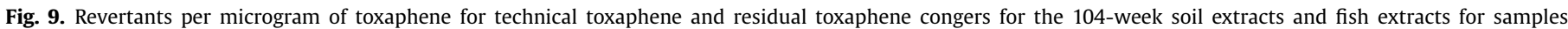
receiving + S9 (A) and $-S 9$ (B) treatments.

of variables that otherwise would have complicated the comparisons. The above analysis also does not address the difference in bioavailability of toxaphene residues. This issue is quite complex and beyond the scope of the current study, but the method of comparing mutagenicity at the same toxaphene dose per plate should compensate for many of these differences.

The overall significance of the author's study to environmental issues is two fold: First, congeners containing more than seven chlorine atoms per molecule can be completely removed from technical-grade toxaphene. The fate of congeners containing seven chlorines or less, including the Hx-Sd and Hp-Sd congeners, was not identified in the authors' study. The Hx-Sd and Hp-Sd congeners seemed to change little after 79 weeks of incubation. Addition of more readily biodegradable organic co-substrate, such as acetone, possibly can provide additional biodegradation, but this option was not investigated.

Secondly, the study showed that toxaphene congeners do not become more mutagenic, per unit of toxaphene residual, upon aging in soils or bioaccumulating in fish. The relative increase of the Hx-Sd and Hp-Sd congeners in soils and fish did not alter the mutagenicity of the toxaphene source. Otherwise, the number of revertants per microgram of toxaphene would have been quite different because the two congeners represented widely different percentages of the residual toxaphene in the technical toxaphene and the fish and soil extracts (see Table 5). These observations indicated statistically that the toxaphene residuals in extracts from aged soils and fish-per microgram of toxaphene-were not more mutagenic than those in technical-grade toxaphene.

\section{Conclusions}

This study produced a number of specific observations that led to the following conclusions:

1. The tests showed a definite reduction in the quantity of toxaphene congeners upon aging in soil. All test evidences indicated that toxaphene was degraded through reductive dechlorination of the higher-chlorinated congeners to lesserchlorinated congeners. Incubation at $25^{\circ} \mathrm{C}$ for 79 weeks under anoxic conditions produced $50 \%$ reduction in the total mass of toxaphene but with essentially complete removal of all congeners having eight or more chlorine atoms per molecule.

2. Tests with both soil and fish extracts showed evidence of an increasing relative amount of two specific congeners, $\mathrm{Hx}-\mathrm{Sd}$ and $\mathrm{Hp}-\mathrm{Sd}$, which contain six and seven chlorine atoms per molecule, respectively. These congeners, respectively, represented $8.7-5.7 \%$ of the residual toxaphene in aged soils and $19.5-14.6 \%$ in fish. These greater relative amounts of Hx-Sd and Hp-Sd congeners in the soil and fish extracts did not show increased mutagenic impacts relative to that produced by technical toxaphene. 
A

+ S9

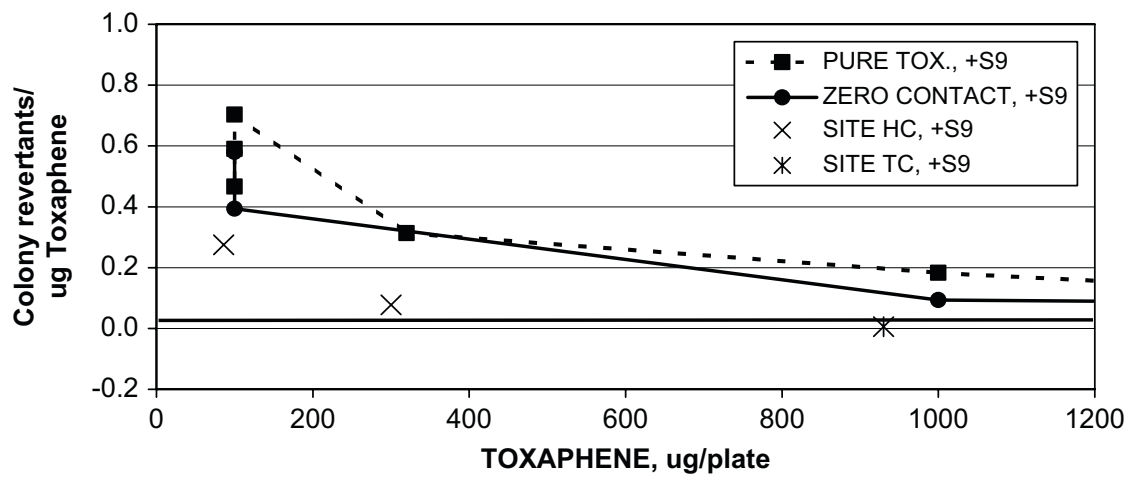

B

-S9

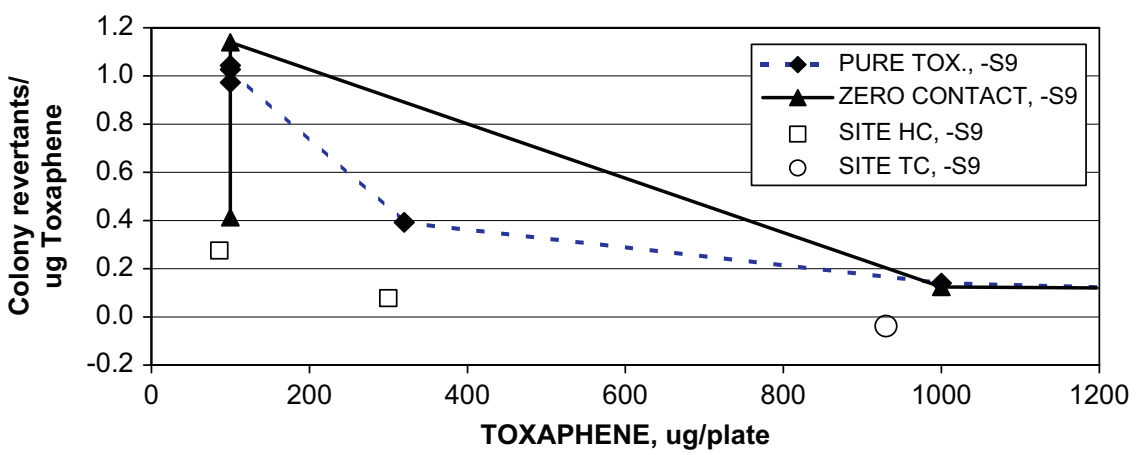

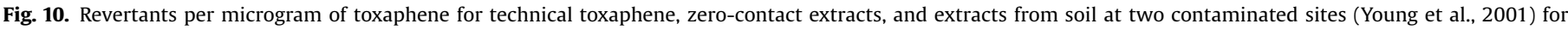
samples receiving $+\mathrm{S} 9$ (A) and $-\mathrm{S9}$ (B) treatment.

3. The mutagenic impact of the toxaphene residuals in aged soil, expressed as colony revertants per microgram of residual toxaphene, statistically was lower than that for technical-grade toxaphene.

4. The mutagenicity of the toxaphene residuals in extracts from fish, expressed as colony revertants per microgram of residual toxaphene, statistically was the same as that of technical-grade toxaphene.

5. Overall, the aged toxaphene residuals in soils and the bioaccumulated toxaphene congeners in fish were not more mutagenic than those in technical-grade toxaphene.

\section{Acknowledgments}

The work described in this paper was conducted under agreements 9C-R570-NASA and 1C-R234-NASA with the Office of Research and Development of the US Environmental Protection Agency, Cincinnati, $\mathrm{OH}$. No humans or experimental animals were used as test subjects in the conduct of the test program.

\section{References}

American Public Health Association, 1998. Standard Methods for the Examination of Water and Wastewater. APHA, Washington, DC.

Barr, J.R., Woolfitt, A.R., Maggio, V.L., Patterson Jr, D.G., 2004. Measurement of toxaphene congeners in pooled human serum collected in three US cities using high-resolution mass spectrometry". Arch. Environ. Contam. Toxicol. 46, 551-556.

Buser, H.R., Haglund, P., Müller, M., Poiger, T., Rappe, C., 2000. Rapid anaerobic degradation of toxaphene in sewage sludge. Chemosphere 40, 1213-1220.

Fingerling, G., Hertkorn, N., Parlar, H., 1996. Formation and spectroscopic investigation of two hexachlorobornanes from six environmentally relevant toxaphene components in soil under anaerobic conditions. Environ. Sci. Technol. 30, 2984-2992.

Hooper, N.K., Ames, B.K., Saleh, M.A., Casida, J.E., 1979. Toxaphene, a complex mixture of polychloroterpenes and a major insecticide, is mutagenic. Science 205, 591-592.

Kidd, K.A., Schindler, D.W., Muir, D.C.G., Lockhart, W.L., Hesslein, R.H., 1995. High concentrations of toxaphene in fishes from a subarctic lake. Science 269, 240-242.

Maron, D.M., Ames, B.N., 1983. Revised methods for the salmonella mutagenicity test. Mutat. Res. 113, 173-215.

Maruya, K.A., Lee, R.F., 1998. Aroclor 1268 and toxaphene in fish from a Southeastern US estuary. Environ. Sci. Technol. 32, 1069-1075.

Maruya, K.A., Walters, T.L., Manning, R.O., 2001. Residues of toxaphene in fin- and shellfish from Terry/Dupree Creek, Georgia, USA. Estuaries 24, 585-596.

McHugh, B., Glynn, D., Nixon, E., McGovern, E., 2003. The occurrence and risk assessment of the pesticide mixture toxaphene in fish from Irish waters. Mar. Environ. Health Issues, Dublin 12.

Mirsatari, S.G., McChesney, M.H., Craigmill, A.C., Winterlin, W.L., Seiber, J.N., 1987. Anaerobic microbial dechlorination: An approach to on-site treatment of toxaphene-contaminated soil. J. Environ. Sci. Health B 22, 663-690.

Mortelmans, K., Haworth, S., Lawlor, T., Speck, W., Tainer, B., Zeiger, E., 1986. Salmonella mutagenicity tests: II. Results from the testing of 270 chemicals. Environ. Mutagenesis 8, 1-26.

Steinberg, M., Kinoshita, F.K., Ballantyne, M., 1998. Mutagenicity studies with toxaphene congeners. Organohalogen Compds. 35, 243-246.

Stern, G.A., Loewen, M.D., Miskimmin, B.M., Muir, D.C.G., Westmore, J.B., 1996 Characterization of two major toxaphene components in treated lake sediment. Environ. Sci. Technol. 30, 2251-2258.

Vetter, W., Kirchberg, D., 2001. Production of toxaphene enantiomers by enantioselective HPLC after isolation of the compounds from an anaerobically degraded technical mixture. Environ. Sci. Technol. 35, 960-965.

Vogel, H.J., Bonner, D.M., 1956. Acetylornithinase of Escherichia coli: Partial purification and some properties. J. Biol. Chem. 218, 97-106.

Young, J.C., Freeman, A.D., 2005. Biodegradation of toxaphene in aerobic, anoxic, and alternating oxic/anoxic soil environments. Final Report for Agreement 1C-R234-NASA, Office of Research and Development, US EPA, Cincinnati, $\mathrm{OH}$.

Young, J.C., Freeman, A.D., Lorince, T., 2001. Bioavailability and mutagenicity of toxaphene after aging in anoxic soil environments. Final Report for EPA Project 9C-R570-NASA. Office of Research and Development, US EPA, Cincinnati, OH. 